\title{
Kinetics of the Thermal Decomposition of Dimethylmercury. II. Carbon-13 Isotope Effect
}

\author{
Morley E. Russelt and Richard B. Bernstein \\ Chemistry Department, University of Michigan, Ann Arbor, Michigan
}

(Received July 17, 1958)

\begin{abstract}
The $\mathrm{C}^{13}$ kinetic isotope effect in the pyrolysis of gaseous dimethylmercury has been studied in the presence and absence of cyclopentane inhibitor from $290-375^{\circ} \mathrm{C}$ for the inhibited and $290-350^{\circ} \mathrm{C}$ for the uninhibited reactions. The isotopic fractionation factor $(S)$ is defined as the ratio of rate constants for the decomposition of $\mathrm{Hg}\left(\mathrm{C}^{12} \mathrm{H}_{3}\right)_{2}$ ws $\mathrm{C}^{12} \mathrm{H}_{3} \mathrm{HgC}^{13} \mathrm{H}_{3} . S$ shows a strong dependence upon the degree of inhibition of the methyl radical chain, which, in turn, is a function of the ratio of cyclopentane to dimethylmercury. $S$ is also a function of the total pressure.

The dependence of $S$ upon the degree of inhibition agrees quantitatively with the predictions of the mechanism proposed in $\mathrm{I}$. The pressure effect on the isotope effect is attributed to the unimolecular nature of the rate determining step ( $\mathrm{Hg}-\mathrm{C}$ bond rupture) and is consistent with the over-all kinetics.

The isotope rate factor in the fully inhibited high-pressure limit, $\alpha$, is $1.034 \pm 0.002$ (essentially independent of temperature over the range studied), compared to a value of $1.011 \pm 0.001$ for the uninhibited (chain) decomposition.
\end{abstract}

\section{INTRODUCTION}

$\mathbf{T}$ HE previous paper, ${ }^{1} \mathrm{I}$, dealt with the kinetics of the pyrolysis of dimethylmercury (DMM) alone and in the presence of excess cyclopentane inhibitor. The results indicated the existence of a short methyl radical chain in the (uninhibited) decomposition. The present paper reports a concurrent study of the $\mathrm{C}^{13}$ kinetic isotope effect in the reaction.

The isotope effect may elucidate the mechanism as follows. For the various nonchain reaction schemes proposed in the literature it may be seen that the $\mathrm{C}^{13}$ content of the methane produced should reflect that of the methyl radicals formed in the initial $\mathrm{Hg}-\mathrm{C}$ bond rupture. Thus any $\mathrm{C}^{12} / \mathrm{C}^{13}$ fractionation associated with the primary process should be evident in the $\mathrm{CH}_{4}$ and should be independent of the presence of a methyl radical "sink" such as cyclopentane (or toluene). For a $\mathrm{CH}_{3}$ chain mechanism, however, it is seen that the isotope effect will be reduced ("diluted") by an amount depending upon the chain length because of the isotopically nonspecific $\mathrm{CH}_{3}$ radicals from the decomposition of the $\mathrm{CH}_{3} \mathrm{HgCH}_{2}$ radicals. ${ }^{2}$ The present isotopic results have confirmed the basic features of the chain mechanism near $300^{\circ} \mathrm{C}$.

In addition, the isotope effect has been evaluated in the fully inhibited, high-pressure limit. This value, the isotope rate factor, $\alpha$, is shown to be the ratio of the unimolecular rate constants for the decomposition of $\mathrm{Hg}\left(\mathrm{C}^{12} \mathrm{H}_{3}\right)_{2}$ ขs $\mathrm{C}^{12} \mathrm{H}_{3} \mathrm{HgC}^{13} \mathrm{H}_{3}$. It may be expressed in terms of the so-called intramolecular and intermolecular isotope effects, which in turn may be estimated theoretically by means of the Bigeleisen equation, assuming certain simplified models of the transition state.

${ }^{1}$ M. E. Russell and R. B. Bernstein, J. Chem. Phys. 30, 607 (1959), preceding paper.

2 See A. Maccoll and P. J. Thomas, J. Chem. Phys. 23, 1722 (1955) and Friedman, Bernstein, and Gunning, J. Chem. Phys. $23,109,1722(1955)$, for a somewhat similar situation in the ethyl bromide pyrolysis.

\section{EXPERIMENTAL}

The experimental procedures were outlined in I. The mass spectrometer for isotopic assay was a Niertype double-beam isotope-ratio instrument modified $^{3}$ with a vibrating reed electrometer amplifier. Analyses were performed by alternating samples with tank $\mathrm{CO}_{2}$ and recording the ratio of the $45 / 44$ peak ratios (tank vs sample) in the usual way. During every series of analyses a reference sample from the complete combustion of DMM was measured. The isotope fractionation factor $S$ is defined

$$
S=\frac{\left(\mathrm{C}^{12} \mathrm{H}_{4}\right) /\left(\mathrm{C}^{13} \mathrm{H}_{4}\right)}{(1-N) / N},
$$

where the isotope ratio in the methane is that of the $\mathrm{CO}_{2}$ from its quantitative combustion and $N=$ atom fraction of $\mathrm{C}^{13}$ in the original DMM similarly obtained. Correction of $S$ to zero extent of reaction was made using the standard logarithmic formula $S^{\circ}=$ $\ln (1-f) / \ln (1-f / S)$, where $f=$ fraction of substrate reacted. For $f \leq 0.1$ (the usual case), the simplified form ${ }^{4}$ was used: $S^{\circ}-1=(S-1)(1+f / 2)$.

In the course of the present work the $\mathrm{C}^{13}$ content of various compounds of interest was determined relative to that of the standard tank $\mathrm{CO}_{2}$. Table I lists the ratio of $\mathrm{C}^{12} / \mathrm{C}^{13}$ in $\mathrm{CO}_{2}$ from quantitative $( \pm 1 \%)$ combustion of the compound to that in the tank $\mathrm{CO}_{2}$. The large anomalous $\mathrm{C}^{12}$ enrichment ( $\mathrm{C}^{13}$ deficiency) of the DMM is attributable to that of the $\mathrm{CH}_{3} \mathrm{I}$ used in its preparation; the origin of the anomaly in the isotopic composition of the $\mathrm{CH}_{3} \mathrm{I}$ is currently being investigated.

\section{RESULTS}

\section{A. Decomposition of DMM Alone}

Table II summarizes the data on $\mathrm{C}^{12} / \mathrm{C}^{13}$ fractionation in the pyrolysis of DMM under various conditions.

\footnotetext{
${ }^{3}$ M. Dole, Chem. Revs. 51, 266 (1952); C. R. McKinney et al., Rev. Sci. Instr. 21, 724 (1950).

${ }^{4}$ See Friedman et al., reference 2.
} 
TABLE I. $\mathrm{C}^{12} / \mathrm{C}^{13}$ enrichment of various compounds relative to tank $\mathrm{CO}_{2}$.

\begin{tabular}{ll}
\hline Compound & $\mathrm{C}^{12} / \mathrm{C}^{13}$ ratio rel. to $\mathrm{CO}_{2}$ \\
\hline $\mathrm{Hg}\left(\mathrm{CH}_{3}\right)_{2}$ & $1.072 \pm 0.001$ \\
$\mathrm{CH}_{3} \mathrm{I}^{\mathrm{a}}$ & $1.077^{2} \pm 0.001$ \\
$\mathrm{C}_{6} \mathrm{H}_{10}{ }^{\mathrm{b}}$ & $1.001_{3} \pm 0.000_{7}$ \\
$\mathrm{CH}_{4}{ }^{\circ}$ & $1.027_{6} \pm 0.000_{7}$ \\
\hline
\end{tabular}

a Eastman Organic Chemicals No. 164.

b Phillips Petroleum Company.

- Matheson Company.

As already noted, the values are obtained from consideration of the methane product. Similar but less extensive data were recorded for the $\mathrm{C}_{2}-\mathrm{C}_{4}$ hydrocarbon fraction; values of $S^{\circ}$ of approximately 1.015 were obtained.

\section{B. Decomposition of DMM with Cyclopentane}

For the cyclopentane-inhibited decomposition ${ }^{5}$ the isotope effect was found to be a function of the ratio of DMM to cyclopentane $(Q)$ and the total pressure. Figure 1 shows the dependence of $S^{\circ}$ upon $Q$ at $303^{\circ} \mathrm{C}$, with an average initial total pressure $\left(P_{0 t}\right)$ of $293 \mathrm{~mm}$ $\mathrm{Hg}$ (within limits of $\pm 10 \%$ ).${ }^{6}$ Further but less extensive data on the dependence of $S^{\circ}$ upon $Q$ at $290,330,360$, and $375^{\circ} \mathrm{C}$ were obtained. The initial slopes of the $S^{0}$ vs $Q$ curves showed no apparent temperature dependence (within the rather large experimental uncertainty in the slope determinations).

Figure 2 shows the dependence of $S^{0}$ upon the total pressure at $360^{\circ} \mathrm{C}$ for $Q=0.17 \pm 0.01$. The influence of the pressurizing gases $\left(\mathrm{CO}_{2}\right.$ and $\mathrm{SF}_{6}$; pressure of $\mathrm{DMM}+\mathrm{C}_{5} \mathrm{H}_{10}$ was $c a 95 \mathrm{~mm} \mathrm{Hg}$ for these experiments) on the isotope effect is apparent. The plot of $S^{0}$ vs reciprocal pressure facilitates extrapolation to the

TABLE II. $\mathrm{C}^{12} / \mathrm{C}^{13}$ isotope effect in the pyrolysis of DMM.

\begin{tabular}{ccc}
\hline \hline$T\left({ }^{\circ} \mathrm{C}\right)$ & $P_{0}(\mathrm{~mm} \mathrm{Hg})$ & $S^{0}$ \\
\hline 287.8 & 77.2 & 1.0123 \\
292.1 & 77.1 & 1.0114 \\
327.4 & 70.8 & 1.0107 \\
327.5 & 71.1 & 1.0117 \\
332.2 & $701.0^{\mathrm{a}}$ & 1.0095 \\
332.5 & 65.0 & 1.0099 \\
348.5 & 78.4 & 1.0108 \\
349.1 & 69.5 & 1.0108
\end{tabular}

Av $\overline{1.011 \pm 0.001}$

${ }^{\mathrm{a}} \mathrm{SF}_{6}$ (Matheson Company) used as pressurizing gas; $P_{0}(\mathrm{DMM})=64.2 \mathrm{~mm} \mathrm{Hg}$.

'It was shown [Ph.D. dissertation of M. E. Russell, University of Michigan (1958) available from University Microfilms, Ann Arbor, Michigan] by the tracer technique that essentially none of the carbon in the methane product originated from the cyclopentane, with $>98 \%$ derived from the DMM decomposed.

${ }^{6}$ Not shown on the graph are a number of points at higher values of $Q$ (with correspondingly smaller values of $S^{0}$ ) for which the total pressure was not comparable with the rest of the series.

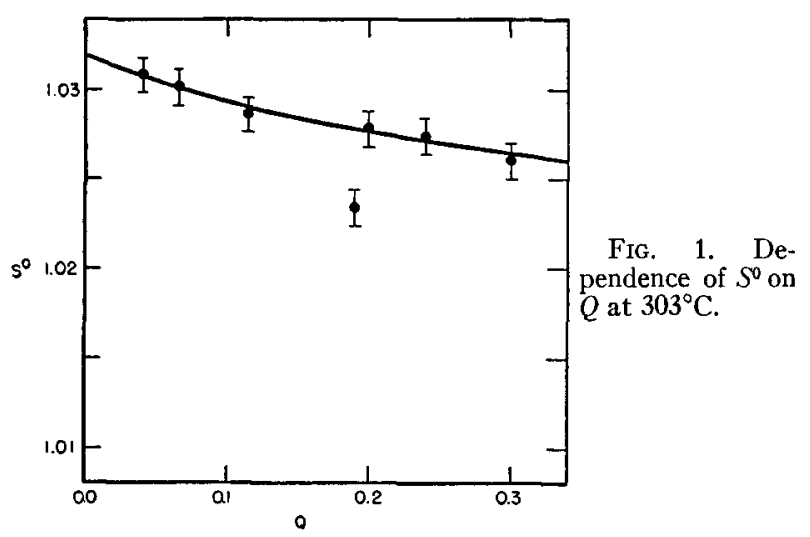

high-pressure limiting value of the isotope effect. Fewer data at other temperatures suggested that the change of the initial slope, $\left[d S^{\circ} / d(1 / P)\right]_{0}$, with temperature is small.

The approximation has been made that both $\left[d S^{0} / d Q\right]_{0}$ and $\left[d S^{0} / d(1 / P)\right]_{0}$ are independent of temperature. Thus the values of $S^{0}$ (for all experiments for which $Q \leq 0.21$ ) were corrected to the completely inhibited $(Q=0)$ and high-pressure $(1 / P=0)$ limit, designated as $\alpha$. Table III lists the results, giving the value of $Q$ and $P_{0 t}$ at which the $S^{0}$ was obtained, together with the "fully corrected" unimolecular isotope rate factor, $\alpha$, at the given temperature.

Figure 3 is a plot of $\alpha$ vs temperature. The half-width of a rectangle is the average deviation of the temperature (for a given set) while the half-height is the estimated probable error of the mean $\alpha$.

\section{DISCUSSION OF RESULTS}

Comparison of the isotope fractionation data for the inhibited and the uninhibited decompositions (isotope effect of $3.4 \%$ vs $1.1 \%$, respectively) leads to the same conclusion regarding the chain character of the pyrolysis as already derived (I) on the basis of the kinetic data. The isotope effect for the uninhibited decomposition is low as the result of the methyl radical chain, which may be suppressed by the addition of cyclopentane. ${ }^{7}$

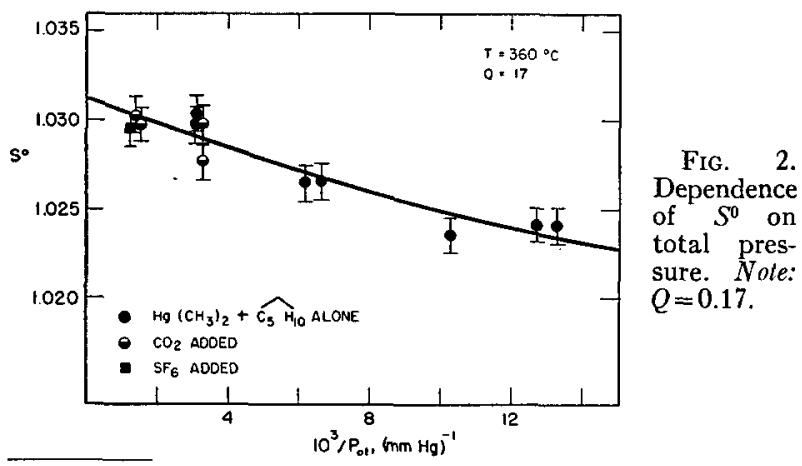

${ }^{7}$ It should be noted that the increase in the isotope effect upon addition of cyclopentane does not occur by virtue of the pressure effect alone; from Table II, the addition of a great excess of $\mathrm{SF}_{6}$ to DMM caused no significant change in the (low) isotope effect of $1.1 \%$. 
The equations for the relevant isotopic reactions in the fully inhibited pyrolysis of DMM are

$$
\begin{gathered}
\mathrm{C}^{12} \mathrm{H}_{3} \mathrm{HgC}^{12} \mathrm{H}_{3} \rightarrow \mathrm{HgC}^{12} \mathrm{H}_{3}+\mathrm{C}^{12} \mathrm{H}_{3}, \\
\mathrm{HgC}^{12} \mathrm{H}_{3}+\mathrm{C}^{13} \mathrm{H}_{3}, \\
\mathrm{C}^{12} \mathrm{H}_{3} \mathrm{HgC}^{13} \mathrm{H}_{3} \\
\mathrm{C}^{13} \mathrm{HgC}_{3} \mathrm{HgC}^{13} \mathrm{H}_{3}+\mathrm{C}^{12} \mathrm{H}_{3}, \\
\mathrm{HgC}^{12} \mathrm{H}_{3} \rightarrow \mathrm{HgC}+\mathrm{C}^{12} \mathrm{H}_{3}, \\
\mathrm{HgC}^{13} \mathrm{H}_{3} \rightarrow \mathrm{Hg}+\mathrm{C}^{13} \mathrm{H}_{3}, \\
\mathrm{C}^{12} \mathrm{H}_{3}+\mathrm{C}_{5} \mathrm{H}_{10} \rightarrow \mathrm{C}^{12} \mathrm{H}_{4}+\mathrm{C}_{5} \mathrm{H}_{9}, \\
\mathrm{C}^{13} \mathrm{H}_{3}+\mathrm{C}_{5} \mathrm{H}_{10} \rightarrow \mathrm{C}^{13} \mathrm{H}_{4}+\mathrm{C}_{5} \mathrm{H}_{9} .
\end{gathered}
$$

Assuming (1) complete inhibition (i.e., all $\mathrm{CH}_{3}$ radicals abstract $\mathrm{H}$ from $\mathrm{C}_{5} \mathrm{H}_{10}$ to form $\mathrm{CH}_{4}$ ), (2) rapid and quantitative decomposition of $\mathrm{HgCH}_{3}$ radicals, (3) zero extent of reaction, and (4) tracer level of $\mathrm{C}^{13}$ in the DMM (e.g., 1.1 atom $\% \mathrm{C}^{13}$ ), it may be shown readily that

$$
S^{0}=k_{1 A} /\left(k_{1 B}+k_{1 C}\right) \text {. }
$$

In the high-pressure limit $S^{0}$ becomes $\alpha$, which may thus be considered to be the ratio of the unimolecular rate constants for the decomposition of $\mathrm{Hg}\left(\mathrm{C}^{12} \mathrm{H}_{3}\right)_{2}$ vs $\mathrm{C}^{12} \mathrm{H}_{3} \mathrm{HgC}^{13} \mathrm{H}_{3}$. Using the usual nomenclature, the intramolecular isotope effect is defined as the ratio $k_{1 C} / k_{1 B}$ and the intermolecular isotope effect as $k_{1 A} / 2 k_{1 B}$. The intramolecular effect represents the relative probability of rupture of the $\mathrm{Hg}-\mathrm{C}^{12}$ vs the $\mathrm{Hg}-\mathrm{C}^{13}$ bond in a given molecule of $\mathrm{C}^{12} \mathrm{H}_{3} \mathrm{HgC}^{13} \mathrm{H}_{3}$; the intermolecular effect is the relative rupture probability for scission of the $\mathrm{Hg}-\mathrm{C}^{12}$ bond in a molecule

of $\mathrm{Hg}\left(\mathrm{C}^{12} \mathrm{H}_{3}\right)_{2}$ is the $\mathrm{Hg}-\mathrm{C}^{13}$ bond in a molecule of $\mathrm{C}^{12} \mathrm{HgC}^{13} \mathrm{H}_{3}$.

For the derivation of the functional relation between $S^{0}$ and $Q$ in the case of incomplete inhibition, a more extensive set of equations is required. Assuming (in addition to assumptions 2,3 , and 4 above) that (5) the mechanism proposed in I is essentially correct, (6) the only isotopically specific step is the rupture of the $\mathrm{Hg}-\mathrm{C}$ bond in DMM, and (7) radical-radical reactions are of negligible importance, the following are the relevant isotopic equations ${ }^{8}$ :

$$
\begin{aligned}
& \mathrm{Hg}\left(\mathrm{CH}_{3}\right)_{2} \longrightarrow 2 \mathrm{CH}_{3}+\mathrm{Hg} \quad k_{1 A} \\
& \mathrm{C}^{*} \mathrm{H}_{3} \mathrm{HgCH}_{3} \longrightarrow \mathrm{CH}_{3}+\mathrm{C}^{*} \mathrm{H}_{3}+\mathrm{Hg} \quad k_{1 B C} \\
& \mathrm{Hg}\left(\mathrm{C}^{*} \mathrm{H}_{3}\right)_{2} \rightarrow 2 \mathrm{C}^{*} \mathrm{H}_{3}+\mathrm{Hg} \quad k_{1 D} \\
& \mathrm{CH}_{3}+\mathrm{Hg}\left(\mathrm{CH}_{3}\right)_{2} \rightarrow \mathrm{CH}_{4}+\mathrm{CH}_{3}+\mathrm{CH}_{2}+\mathrm{Hg} \quad k_{3} \\
& \mathrm{CH}_{4}+\mathrm{C}^{*} \mathrm{H}_{3}+\mathrm{CH}_{2}+\mathrm{Hg} \quad k_{3} / 2 \\
& \mathrm{CH}_{3}+\mathrm{CH}_{3} \mathrm{HgC}^{*} \mathrm{H}_{3} \\
& \mathrm{CH}_{4}+\mathrm{CH}_{3}+\mathrm{C}^{*} \mathrm{H}_{2}+\mathrm{Hg} \quad k_{3} / 2 \\
& \mathrm{CH}_{3}+\mathrm{Hg}\left(\mathrm{C}^{*} \mathrm{H}_{3}\right)_{2} \rightarrow \mathrm{CH}_{4}+\mathrm{C}^{*} \mathrm{H}_{3}+\mathrm{C}^{*} \mathrm{H}_{2}+\mathrm{Hg} \quad k_{3} \\
& \mathrm{C}^{*} \mathrm{H}_{3}+\mathrm{Hg}\left(\mathrm{CH}_{3}\right)_{2} \rightarrow \mathrm{C}^{*} \mathrm{H}_{4}+\mathrm{CH}_{3}+\mathrm{CH}_{2}+\mathrm{Hg} \quad k_{3} \\
& \mathrm{C}^{*} \mathrm{H}_{4}+\mathrm{C}^{*} \mathrm{H}_{3}+\mathrm{CH}_{2}+\mathrm{Hg} \quad k_{3} / 2 \\
& \mathrm{C}^{*} \mathrm{H}_{3}+\mathrm{CH}_{3} \mathrm{HgC} * \mathrm{H}_{3} \\
& \mathrm{C}^{*} \mathrm{H}_{4}+\mathrm{CH}_{3}+\mathrm{C}^{*} \mathrm{H}_{2}+\mathrm{Hg} \quad k_{3} / 2 \\
& \mathrm{C}^{*} \mathrm{H}_{3}+\mathrm{Hg}\left(\mathrm{C}^{*} \mathrm{H}_{3}\right)_{2} \rightarrow \mathrm{C}^{*} \mathrm{H}_{4}+\mathrm{C}^{*} \mathrm{H}_{3}+\mathrm{C}^{*} \mathrm{H}_{2}+\mathrm{Hg} k_{3} \\
& \mathrm{CH}_{3}+\mathrm{C}_{5} \mathrm{H}_{10} \rightarrow \mathrm{CH}_{4}+\mathrm{C}_{5} \mathrm{H}_{9} \quad k_{4} \\
& \mathrm{C}^{*} \mathrm{H}_{3}+\mathrm{C}_{5} \mathrm{H}_{10} \rightarrow \mathrm{C}^{*} \mathrm{H}_{4}+\mathrm{C}_{5} \mathrm{H}_{9} \quad k_{4}
\end{aligned}
$$

Thus

$$
S^{0}=\left(\frac{N}{1-N}\right) \frac{d\left(\mathrm{CH}_{4}\right) / d t}{d\left(\mathrm{C}^{*} \mathrm{H}_{4}\right) / d t}=\left(\frac{N}{1-N}\right) \frac{\left(\mathrm{CH}_{3}\right)\left\{k_{3}(\mathrm{DMM})\left[(1-N)^{2}+2 N(1-N)+N^{2}\right]+k_{4}\left(\mathrm{C}_{5} \mathrm{H}_{10}\right)\right\}}{\left(\mathrm{C}^{*} \mathrm{H}_{3}\right)\left\{k_{3}(\mathrm{DMM})\left[(1-N)^{2}+2 N(1-N)+N^{2}\right]+k_{4}\left(\mathrm{C}_{5} \mathrm{H}_{10}\right)\right\}},
$$

where $(\mathrm{DMM})=$ total concentration of the (three) isotopic forms of dimethylmercury. Thus

$$
S^{0}=\frac{N}{1-N} \frac{\left(\mathrm{CH}_{3}\right)}{\left(\mathrm{C}^{*} \mathrm{H}_{3}\right)} .
$$

Applying the usual steady-state treatment one solves for the ratio $\left(\mathrm{CH}_{3}\right) /\left(\mathrm{C}^{*} \mathrm{H}_{3}\right)$ and finds that, to a good approximation,

$$
S^{0}=\frac{\left[k_{3}(1-N)(\mathrm{DMM})+k_{4}\left(\mathrm{C}_{5} \mathrm{H}_{10}\right)\right] k_{1 A} / k_{1 B C}+k_{3} N(\mathrm{DMM})}{k_{3} N(\mathrm{DMM})+k_{4}\left(\mathrm{C}_{5} \mathrm{H}_{10}\right)+k_{3}(1-N)(\mathrm{DMM}) k_{1 A} / k_{1 B C}} .
$$

Further simplification results in the expression,

$$
S^{0}=\left(Q k_{3} / k_{4}+1\right) \alpha^{\prime} /\left(1+\alpha^{\prime} Q k_{3} / k_{4}\right),
$$

where $Q=(\mathrm{DMM}) /\left(\mathrm{C}_{5} \mathrm{H}_{10}\right)$ and $\alpha^{\prime}=k_{1 A} / k_{1 B C}$. Thus $S^{0}=\alpha^{\prime}$, when $Q=0$. Then

$$
\frac{S^{0}-1}{\alpha^{\prime}-1}=\left[1+\alpha^{\prime} Q k_{3} / k_{4}\right]^{-1} \text {. }
$$

For $Q k_{3} / k_{4}<0.1,(6)$ is closely approximated by

$$
\frac{S^{0}-1}{\alpha^{\prime}-1}=1-Q k_{3} / k_{4}
$$

The similarity of $\mathrm{Eq}$. (7) to the one relating the

${ }^{8}$ The symbols $\mathrm{C}$ and $\mathrm{C}^{*}$ represent $\mathrm{C}^{12}$ and $\mathrm{C}^{13}$, respectively. In order to simplify (without loss of rigor), the original Steps 2 and 1 have been combined as the new Step 1; similarly for the original Steps 3 and 7 , giving the new Step 3 . 
TABLE III. Values of $S^{0}$ and the completely inhibited high-pressure limit, $\alpha$.

\begin{tabular}{|c|c|c|c|c|}
\hline$T\left({ }^{\circ} \mathrm{C}\right)$ & $Q$ & $\underset{\left(\mathrm{mm}{ }^{P^{\prime}} \mathrm{Hg}\right)}{ }$ & $S^{0}$ & $\alpha$ \\
\hline 290.0 & 0.088 & 300 & 1.0297 & 1.0347 \\
\hline 290.0 & 0.19 & 269 & 1.0253 & 1.0321 \\
\hline 288.5 & 0.21 & 355 & 1.0253 & 1.0319 \\
\hline \multicolumn{3}{|l|}{ Av $289.5 \pm 0.7 \mathrm{a}$} & \multicolumn{2}{|c|}{ Wt. Av $1.0334^{\mathrm{b}} \pm 0.0014^{\mathrm{a}}$} \\
\hline 302.8 & 0.035 & 338 & 1.0307 & 1.0339 \\
\hline 302.9 & 0.065 & 274 & 1.0297 & 1.0342 \\
\hline 306.8 & 0.084 & 304 & 1.0262 & 1.0311 \\
\hline 302.8 & 0.11 & 303 & 1.0286 & 1.0339 \\
\hline 304.2 & 0.19 & 340 & 1.0235 & 1.0298 \\
\hline 302.8 & 0.20 & 297 & 1.0279 & 1.0347 \\
\hline \multicolumn{3}{|l|}{ Av $303.7 \pm 1.2$} & \multicolumn{2}{|c|}{ Wt. Av $1.0330 \pm 0.0015$} \\
\hline 329.6 & 0.032 & 310 & 1.0306 & 1.0339 \\
\hline 329.3 & 0.032 & 311 & 1.0308 & 1.0340 \\
\hline 332.2 & 0.072 & 270 & 1.0291 & 1.0339 \\
\hline 331.0 & 0.088 & 293 & $1.027 \overline{7}$ & 1.0328 \\
\hline 332.2 & 0.088 & 306 & 1.0301 & 1.0351 \\
\hline 331.5 & 0.088 & 220 & 1.0276 & 1.0335 \\
\hline 329.3 & 0.088 & 361 & 1.0296 & 1.0342 \\
\hline 329.2 & 0.19 & 277 & 1.0279 & 1.0346 \\
\hline 329.0 & 0.19 & 270 & 1.0286 & 1.0354 \\
\hline \multicolumn{3}{|l|}{ Av $330.4 \pm 1.2$} & \multicolumn{2}{|c|}{ Wt. Av $1.0341 \pm 0.0006$} \\
\hline 360.4 & 0.032 & 257 & 1.0290 & 1.0328 \\
\hline 361.2 & 0.032 & 216 & 1.0301 & 1.0343 \\
\hline 358.9 & 0.072 & 291 & 1.0282 & 1.0329 \\
\hline 360.0 & 0.088 & 296 & 1.0283 & 1.0334 \\
\hline 359.4 & 0.088 & 318 & 1.0294 & 1.0343 \\
\hline 359.6 & 0.088 & 217 & 1.0293 & 1.0352 \\
\hline 359.5 & 0.17 & 323 & 1.0303 & 1.0362 \\
\hline 359.7 & 0.17 & 326 & 1.0297 & 1.0362 \\
\hline 359.2 & 0.19 & 277 & 1.0295 & 1.0355 \\
\hline 359.8 & 0.19 & 261 & 1.0280 & 1.0349 \\
\hline \multicolumn{3}{|l|}{ Av $359.8 \pm 0.5$} & \multicolumn{2}{|c|}{ Wt. Av $1.0343 \pm 0.0009$} \\
\hline 376.6 & 0.039 & 301 & 1.0318 & 1.0351 \\
\hline 376.2 & 0.039 & 301 & 1.0336 & 1.0371 \\
\hline 377.1 & 0.039 & 299 & 1.0337 & 1.0372 \\
\hline 377.0 & 0.039 & 282 & 1.0322 & 1.0358 \\
\hline 375.2 & 0.051 & 301 & 1.0304 & 1.0343 \\
\hline 375.4 & 0.051 & 306 & 1.0316 & 1.0355 \\
\hline 375.2 & 0.051 & 295 & 1.0317 & 1.0357 \\
\hline 375.6 & 0.051 & 296 & 1.0296 & 1.0336 \\
\hline 370.9 & 0.072 & 242 & 1.0284 & 1.0335 \\
\hline 376.1 & 0.088 & 297 & 1.0285 & 1.0336 \\
\hline 376.5 & 0.088 & 291 & 1.0284 & 1.0335 \\
\hline 376.5 & 0.088 & 294 & 1.0288 & 1.0339 \\
\hline 375.3 & 0.19 & 303 & 1.0263 & 1.0328 \\
\hline 375.8 & 0.19 & 306 & 1.0261 & 1.0326 \\
\hline 375.6 & 0.19 & 290 & 1.0269 & 1.0335 \\
\hline 375.4 & 0.19 & 259 & 1.0264 & 1.0333 \\
\hline \multicolumn{3}{|l|}{ Av $\overline{375.7} \pm 0.8$} & \multicolumn{2}{|c|}{ Wt. Av $1.0346 \pm 0.0012$} \\
\hline
\end{tabular}

- Average deviation from mean.

b Double weighting (within each temperature group) given to experiments with $Q<0.1$.

methane rate constant to $Q$ [Eq. (3) in I] is apparent. From the initial slope of curves such as Fig. $1\left(S^{0} v s Q\right)$, $k_{3} / k_{4}$ may be evaluated. ${ }^{9}$ The value of $k_{3} / k_{4}$ at $303^{\circ} \mathrm{C}$

The observed positive curvature of the $S^{0}$ vs $Q$ curve (Fig. 1) is satisfactorily explained by the hyperbolic form of Eq. (6); however, no attempt at quantitative treatment of data at high $Q$ is warranted in view of the oversimplified reaction mechanism assumed in the present treatment. is seen to be $0.7 \pm 0.2$, which is in fortuitously good agreement with the result $0.7 \pm 0.2$ obtained from the methane rate data reported in I. As noted earlier, no significant trend in $k_{3} / k_{4}$ with temperature was observed, confirming the previous estimate (I) of $E_{3}-$ $E_{4}=0$.

The pressure effect on the isotope effect for a unimolecular decomposition is not unexpected. ${ }^{10}$ The magnitude of the effect observed (Fig. 2) is reasonable in view of the kinetic data (I) on the pressure effect. In the present study the primary concern was the extrapolation to $1 / P_{0 t}=0$ to obtain the limiting highpressure value of the isotope effect for the unimolecular initial $\mathrm{Hg}-\mathrm{C}$ bond rupture step.

It is of interest to compare the experimentally determined $\alpha$ (Table III and Fig. 3) with a theoretical estimate. Using the previous definitions of the intramolecular and intermolecular isotope effects, one obtains the relation,

$$
\epsilon=\frac{\epsilon^{\prime \prime}-\epsilon^{\prime} / 2}{1+\epsilon^{\prime} / 2},
$$

where $\epsilon=\alpha-1, \quad \epsilon^{\prime}=k_{1 C} / k_{1 B}-1$, and $\epsilon^{\prime \prime}=k_{1 A} / 2 k_{1 B}-1$ (in the nomenclature of the mechanism used for the fully inhibited case). To a good approximation Eq. (8) may be simplified: $\epsilon=\epsilon^{\prime \prime}-\epsilon^{\prime} / 2$. Assuming the intramolecular effect to be given by the Slater reduced mass factor ${ }^{\mathrm{Il}}$ (independent of temperature), one calculates $\epsilon^{\prime}=0.038$. By use of the simplified form ${ }^{12}$ of the Bigeleisen equation ${ }^{11(b)}$ for the intermolecular effect, $\epsilon^{\prime \prime}=\epsilon^{\prime}+\delta$ (where $\delta$ is the temperature dependent free energy function), one obtains

$$
\epsilon=\delta+\epsilon^{\prime} / 2 \text {. }
$$

Using the simple "rigid model" approach (i.e., the only normal vibrational frequencies assumed to change in the transition state are those leading to decomposition), and the two frequencies 515 and $550 \mathrm{~cm}^{-1}$

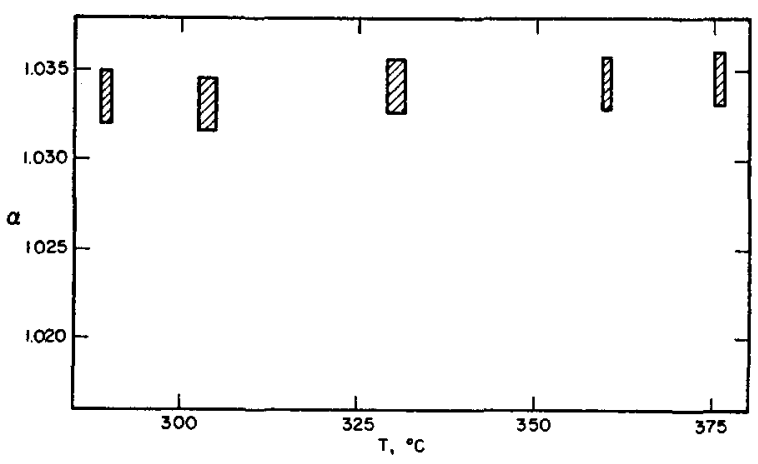

FIG. 3. Temperature dependence of $\alpha$.

${ }^{10}$ R. B. Bernstein, J. Phys. Chem. 56, 893 (1952); R. E. Weston, Jr., J. Chem. Phys. 26, 975 (1957).

11 (a) J. Bigeleisen, J. Phys. Chem. 56, 823 (1952); (b) J. Bigeleisen, J. Chem. Phys. 17, 675 (1949); (c) N. B. Slater, Proc. Roy. Soc. (London) A194, 112 (1948).

12 R. B. Bernstein, J. Chem. Phys. 22, 710 (1954). 
reported $^{13}$ for the $\mathrm{Hg}-\mathrm{C}$ stretching motions, one estimates a value of $\delta=0.004$ at $327^{\circ} \mathrm{C}$, with a slight (normal) negative temperature dependence of the order of $10^{-5}$ (degree) $)^{-1}$. The resulting theoretically estimated value for the isotope effect is $2.3 \%$, appreciably smaller than that $(3.4 \%)$ deduced from the present experiments (Fig. 3). The discrepancy may well be due to the simplifying assumptions made in the calculations. The kinetic data (I) suggest that the rate determining (and isotopically specific) step in the decomposition may not be the rupture of a single $\mathrm{Hg}-\mathrm{C}$ bond but the simultaneous breaking of both $\mathrm{Hg}-\mathrm{C}$ bonds. It is possible that a detailed theoretical calculation based on this model would yield better agreement with experi-

${ }^{13}$ H. S. Gutowsky, J. Chem. Phys. 17, 128 (1949). ment. It must be noted, however, that the negligible temperature dependence observed for $\alpha$ precludes the adoption of a temperature dependent term $\delta$ much larger than that used above; improvement in fitting the data would very likely be associated with an increase in the magnitude of the temperature-independent factor. ${ }^{14}$

\section{ACKNOWLEDGMENTS}

The authors appreciate the financial support of this work by the Michigan Memorial Phenoix Project, the U. S. Atomic Energy Commission Division of Research [Contract AT(11-1)-321], and the Alfred P. Sloan Foundation.

${ }_{14} \mathrm{~J}$. Bigeleisen and M. Wolfsberg, J. Chem. Phys. 21, 1972 (1953); 22, 1264 (1954).

\title{
Superposition of Configurations and Natural Spin Orbitals. Applications to the He Problem*
}

\author{
HaRrison Shuli $†$ ANd PER-Olov LöWdin \\ Chemistry Department, Indiana University, Bloomington, Indiana, and Quantum Chemistry Group, Uppsala University, Uppsala, Sweden
}

(Received October 7, 1958)

\begin{abstract}
The method of superposition of configurations is examined in its application to the helium atom in two cases: a $21 \times 21$ matrix including all configurations up to $\langle 6 s\rangle^{2}$, and a $20 \times 20$ matrix with all configurations up to the 4-quantum level, including angular terms. A new radial limit is established at $-2.87900 \pm$ 0.00003 , and this is used to discuss the convergence of such expansions in Legendre functions. The variation with scale factor is discussed in detail. The wave functions are analyzed in terms of natural spin orbitals (NSO's), which seem to have many advantages. The first NSO bears a striking resemblance to the HartreeFock function, and the first two together provide a close approximation to the solution of the extended Hartree-Fock equations with different orbitals for different electrons. An energy of -2.877924 is obtained for the best $(u, v)$ function found. An analysis of the results suggests that inner orbitals may be better represented by pure exponentials than by Hartree-Fock orbitals whenever additional correlational degrees of freedom are permitted. Expressed in approximate NSO form, the wave function is almost invariant to choice of basis set, provided that the latter is reasonably chosen. In particular, the necessity of including continuum terms along with the discrete hydrogen-like set is demonstrated.
\end{abstract}

\section{INTRODUCTION}

$\mathbf{S}^{\mathrm{u}}$ UPERPOSITION of configurations as a method in the quantum-mechanical treatment of the electronic structure of matter has undergone a remarkable renascence in the last decade. Since the method will undoubtedly be of great importance in the future study of atoms and molecules, it has seemed

\footnotetext{
* Supported in part by grants to H. S. by the National Science Foundation, the Alfred P. Sloan Foundation, and the Research Corporation, and to P.-O. L. by King Gustaf VI Adolf's 70-years Fund for Swedish Culture, the Knut and Alice Wallenberg's Foundation, and the Swedish Natural Science Research Council, and in part by the Aeronautical Research Laboratory, Wright Air Development Center of the Air Research and Development Command, U. S. Air Force through its European Office under contract AF 61 (514) -1200 with Uppsala University.

$\dagger$ John Simon Guggenheim Memorial Foundation Fellow, Uppsala University, 1954-1955. Presently on leave at the Uppsala Quantum Chemistry Group.
}

worthwhile to make a rather detailed study of this method in its application to a simple case, that of the helium atom, and in particular to re-examine the results from the viewpoint of natural spin orbitals as developed by Löwdin ${ }^{1}$ and elaborated by Löwdin and Shull. ${ }^{2}$ We consider first the general details of the computations and the results from a relatively conventional point of view. Subsequently, the results are re-examined from the natural spin orbital viewpoint, and some of the advantages and utility of the latter are demonstrated. Finally we consider some more general aspects of the problem, including in particular some points concerning the choice of basis functions for use with the method of superposition of configurations.

\footnotetext{
${ }^{1}$ P.-O. Löwdin, Phys. Rev. 97, 1474 (1955).

2 P.-O. Löwdin and H. Shull, Phys. Rev. 101, 1730 (1955).
} 